\title{
A new look at the body: teaching surface anatomy from contact with Integrative and complementary health practices
}

\begin{abstract}
The objective of this article is to report on the methodology of teaching surface anatomy from the Integrative and Complementary Health Practices (ICHP) created in the Extension Project "Contact". As a methodology for teaching surface anatomy, especially the dorsal anatomy, the project uses ICPH in medical training. The ICHP were: auriculotherapy, cupping therapy, chiropractic and massage. The project involved 5 professors from different fields of knowledge and 7 medical students from the medical course of the Multicampi School of Medical Sciences of Rio Grande do Norte (MSMS). In this report, we highlight the importance of knowledge of anatomy in medical performance and the use of surface anatomy associated with ICPH as a technique for teaching and learning and developing skills in the evaluation and diagnosis of impairment in the quality of life of people who are related to pain and muscle tension.
\end{abstract}

Keywords: surface anatomy, integrative and complementary practices, teaching methodology, medicine
Volume I 3 Issue 4 - 2020

\author{
Marcel Alves Franco,' 'Vivianne Izabelle de \\ Araújo Baptista, ${ }^{2}$ Rafael Soares Dias, ${ }^{2}$ Renata \\ de Abreu Neves Salles, ${ }^{2}$ Milena de Oliveira \\ Aguiar, ${ }^{3}$ Maria Isabel Brandão de Souza \\ Mendes, ${ }^{4}$ Iraquitan de Oliveira Caminha' \\ 'Associated Postgraduate Program in Physical Education (UPE/ \\ FUPB), Brazil \\ ${ }^{2}$ Multicampi School of Medical Sciences of Rio Grande do \\ Norte (MSMS/FURN), Brazil \\ ${ }^{3}$ School of Educational Excellence of Rio Grande do Norte \\ (FATERN-ESTÁCIO), Brazil \\ ${ }^{4}$ Federal University of Rio Grande do Norte, Brazil
}

\begin{abstract}
Correspondence: Marcel Alves Franco,Associated Postgraduate Program in Physical Education UPE-FUPB, Brazil, Arnóbio Marquês Street, 310 - Santo Amaro, 50100 -130, Recife - PE, Brazil, Tel +55 (84) 99898-50I2,

Email macfrancol@gmail.com
\end{abstract}

Received: July 15, 2020 | Published: August 04, 2020

\begin{abstract}
Abbreviations: ICHP, integrative and complementary health practices; MSMS, multicampi school of medical sciences; FURN, federal university of rio grande do norte; NPICP, national policy of integrative and complementary practices. WHO, world health organization. FUSC, federal university of santa catarina; PHC, primary health care
\end{abstract}

\section{Introduction}

The study of anatomy is fundamental to medicine. The human body is the focus of daily interventions and investigations. Nevertheless, it is observed that medical students have a feeling of insecurity when they need to apply anatomical knowledge during clinical practice. ${ }^{1-3}$ This may be related to the fact that the classical approach to anatomy in health courses occurs through contact with cadaveric and static bodies, making it difficult for the student to establish an interdisciplinary link between the study of human morphology in clinical contexts ${ }^{4}$. Therefore, it is important to reverse the reasoning process for effective anatomical learning, through clinical problematization, anatomical correlations and case studies, integrating teaching. ${ }^{5}$ Surface anatomy is an anatomy modality dedicated to understanding the "living" body. It uses techniques of inspection and palpation of anatomical structures, mainly musculoskeletal, to make learning more contextualized with reality. ${ }^{2}$ In addition, when examining the surface of the human body, the student has the opportunity to evaluate the body as whole, phenotypes, as well as to interpret the signs of tensions in order to promote an effective treatment.

With muscle tensions causing pain and postural problems, in Brazil, it is identified that $80 \%$ of Brazilian workers are affected by this complication, which represents the second biggest cause of absences. ${ }^{6}$ Pain is a feeling detected by nervous system sensors, with different types, location and duration, that can also be a sign of a process of illness that may require immediate attention. ${ }^{7}$ In the case of students, postural problems are related to the inadequate transport of school materials, backpacks, and also due to the time they spend sitting. ${ }^{8}$ Musculoskeletal complaints are quite common in medical practice. However, in the basic curriculum of undergraduate medicine, the specific contents for musculoskeletal anatomy are not well delimited, especially regarding the back region. ${ }^{9}$

At this moment, we have an opportunity to outline our strategy to develop the content of human anatomy and promote knowledge with forms of non-invasive forms of treatment of these issues of postural problems, muscle pain and tension. Therefore, we organized our project with members of our team of teachers of the institution, trained to work with some of the ICHP, especially auriculotherapy, cupping therapy, Seitai (Japanese chiropractic) and massage, besides professionals specialized in the studies of composition of musculoskeletal structures related to body posture and its alignment, that is, the back muscles. That is, a multidisciplinary team with potential for the development of anatomical studies and enable the form of treatment with the ICHP. The ICHP has always been incorporated into a society's cultural practice, however, despite a modest production, with scientific validation, the ICHP is beginning to be disseminated in health systems. ${ }^{10}$ On the international stage, the 1978 Alma-Ata Declaration ${ }^{11}$ marks the reflection of the insertion of these practices in parallel to the conventional allopathic model, initiating a process of reorienting health services. The World Health Organization (WHO) begins to develop guidelines and recommendations at several health 
conferences, in order to encourage countries to implement ICHP or alternative and complementary medicine, as it is called on the global stage ${ }^{12,13}$ corroborating an economic and social bias. ${ }^{14}$

In Brazil, the ICHP were incorporated into the Unified Health System (UHS) in Brazil by the Ministry of Health through the National Policy of Integrative and Complementary Practices (NPICP)..$^{15}$ It is known that ICHP contributes to the fundamental principles of UHS: universality, comprehensiveness and equity, by "acting in the fields of disease prevention and health promotion, maintenance and recovery based on a model of humanized assistance and focused on the health and integrality of the individual". ${ }^{15-17}$

The study by Nascimento \& Tesser ${ }^{16}$ discuss the situation of traditional complementary and integrative medicine in Primary Health Care (PHC), in UHS, in particular, based on training and research in this field. Registering 29 types of different modalities, the study points out that $80 \%$ of the offer of these practices happens in the scope of PHC, the most common being body practices, herbal medicine or medicinal plants, acupuncture and homeopathy. The authors consider that ICHP are a potential resource against medicalization in PHC, favoring a diversity of approaches to deal with each person's condition, due to its large number of interpretive and therapeutic options. In the same work, the authors criticize that many of the professionals carry out their training through their own initiative.

In order to achieve health attention, we discuss the body and how it is treated in Western rationality, which also impacts its way of conceiving medicine. In our project, we understand that man is a being who thinks, feels and acts, ${ }^{17}$ or in other words, "by the body I perceive, by the body I analyze and through it I coexist in the world." ${ }^{17: 83}$

The Extension Project "Contact" was a space for learning this new look for the body. A look that is not limited to causality or linearity in the health-disease process, but that recognizes the dynamics of life and, as historicity, understands that the body also tells its history through its marks, pains and smiles, that is, in a way of language that is not verbalized.

The reconciliation of a holistic worldview with ICHP is necessary in health professionals training to increase the wellness and life quality. The study by Jong et al. ${ }^{19}$ points out that health system users in the Netherlands would like the (general practitioner) doctor to question and learn about ICHP. Garcia ${ }^{20}$ carries out a work that highlights the implementation of yoga and meditation practice for police officers through the "Mind-Body Medicine Workplace Wellness" Program. The program's proposal is innovative, since it highlights the mindbody union and the benefits that this type of approach can promote in the area of patient-oriented healing, which is different from the approach that focuses on illness and not physical and mental health of the person. In particular, from police officers who perform stressful work at direct risk to their lives. Ke's study, ${ }^{21}$ presents a discussion on modern holistic medicine from Traditional Chinese Medicine and presents us with the proposal to incorporate the models of thinking, forms of treatment and clinical experience of Chinese medicine, so that in the 21 st century, these forms of medicine can be complementary. In this study, the proposal of modern holistic medicine is understood from the treatment of the patient as a whole, integrating body, mind and spirit so that a form of healing can be carried out effectively. Considering the scenario of the consequences of suffering with pain, Hegyi, Henrik and Zoltán ${ }^{7}$ studied the acupuncture as a form of therapy for the treatment of pain and brings examples such as carpal tunnel syndrome, fibromyalgia, lower back pain, migraine, menstrual clots, tennis elbow, myofascial pain, neck pain, osteoarthritis and chronic knee pain, among others.

Based on the NPICP, we will be "considering the individual in his dimension global - without losing sight of his singularity, when explaining his processes of illness and health". ${ }^{15,8}$

Thus, the objective of this article is to report the experience of the construction of the teaching methodology of Surface anatomy (or Surface Anatomy), especially that of the back, from the ICHP, and to point out implications of this teaching-learning process in medical education.

\section{Material and methods}

The Extension Project "Contact: studies in surface anatomy from Integrative and Complementary Health Practices (ICHP)" was carried out at the Multicampi School of Medical Sciences of Rio Grande do Norte, a unit of the Federal University of Rio Grande do Norte (MSMS/ FURN), in the city of Caico, in the state of Rio Grande do Norte, Brazil. The project aimed to promote the study of musculoskeletal structures through surface anatomy, from the treatment of muscle pain and tensions with ICHP. In addition to this objective, the project aimed to stimulate the doctor-patient relation in a sensitive and professional quality way.

The months of January and February were dedicated to the development of the project. Teachers and institutional staff assess the conditions for carrying out the activities and how they would be carried out. The project was carried out between April and October 2018 and included moments of training in ICHP's surface anatomy, carried out in the form of workshops and outpatient care for people from the MSMS internal and external community, who, in a first evaluation, would be suffering from muscle tensions or pain from those tensions. In November, students and teachers participated in academic events to present the project and its activities. December was dedicated to the institutional report.

This is an experience report linked to the Extension Project "Contact: studies in surface anatomy from Integrative and Complementary Practices in Health", developed at the Bachelor of Medicine (MSMS). The project was created in 2018, with the objective of contributing to the students' difficulties regarding the knowledge of human anatomy and enabling the approach of the ICHP. The composition of the project is made by 5 teachers, one of Physiotherapy, two of Nursing, one of Medicine (Family Health) and one of Physical Education. In addition to the teachers, 7 students from the institution's medical course participated. Students who participated in the project must be attending at least the third period of the course, as they have prior preparation for public reception, active listening and have some knowledge of the anatomy of the body. For its accomplishment, we count on the articulation with the Laboratory of Morphofunctional Skills, the Clinic-School and its outpatient clinic, and we received technical support from the administration and the information technology sector of the MSMS, and it was funded by the Pro-Rectory of Extension of FURN. The Project started together with the institution's calendar. Being a weekly meeting, lasting 2 hours each meeting. We can see its organization in Table 1. 
Table I Schedule of activities of the Extension Project "Contact."

\begin{tabular}{|c|c|c|c|}
\hline Month & Integrative and complementary practice & Activities & \\
\hline April & Postural Assessment and Stretching & $\begin{array}{l}\text { i. } \\
\text { ii. } \\
\text { iii. } \\
\text { iv. } \\
\text { v. }\end{array}$ & $\begin{array}{l}\text { Presentation of the Project; } \\
\text { Presentation of ICHP to be developed in the outpatient clinic; } \\
\text { Discussion about the integral look on the body; Pain and quality of life; } \\
\text { "Taboos" of contact with the body; } \\
\text { Experience of postural evaluation and stretching of the members; } \\
\text { Organization of knowledge of surface anatomy (main postural structures). }\end{array}$ \\
\hline May & $\begin{array}{l}\text { Reflexology } \\
\text { Auriculotherapy }\end{array}$ & $\begin{array}{l}\text { i. } \\
\text { ii. } \\
\text { iii. }\end{array}$ & $\begin{array}{l}\text { Study of the sympathetic and parasympathetic nervous system. } \\
\text { Anatomy of the ear pavilion; } \\
\text { Auriculotherapy workshop. }\end{array}$ \\
\hline June & (Institutional recess) & -----------. & 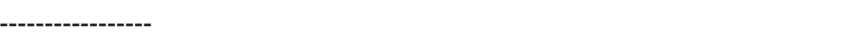 \\
\hline July & Massage & i. & Muscle biodynamics (flexion/extension and contraction/relaxation). \\
\hline August & Cupping therapy & ii. & Trigger-points and myofascial pain. \\
\hline September & Seitai (Japanese chiropractic) & iii. & $\begin{array}{l}\text { Study of the autonomic nervous system; vertebral manipulation study } \\
\text { (Maitland Concept). }\end{array}$ \\
\hline October & (All) & iv. & $\begin{array}{l}\text { Conclusion of outpatient care; } \\
\text { Evaluation of the Project. }\end{array}$ \\
\hline
\end{tabular}

In accordance with the methodology described above, we now move on to the project execution report

\section{The contact project}

For the production of knowledge in anatomy, workshops were held with the students' active participation, under the perspective of the "living body" studied the anatomical structures. We are talking about the perspective of the body that Fensterseifer ${ }^{22}$ presents us. Körper, has the relation of the anatomized body, dead body, from the study of anatomy known in the morphology laboratories. Inanimate object, without speech, without listening, dissected; Leib, on the other hand, is the lived body, whose subjective context, sense and meaning are present. They are the bodies that tell us their stories of life, in their personal names and in the punctuation of each one of them.

To discuss the body in its relationship with the knowledge of Anatomy, Medeiros ${ }^{23}$ situates how body perception developed from the anatomical perspective to the phenomenological body. Not following a historical linearity, the author points out that we can see the body from the historical perspective of science and another from philosophy.

Anatomy arises as a result of the evolution of dissecting techniques, around the sixteenth and seventeenth century in the historical moment of the Renaissance, being known as a new science..$^{23}$ The phenomenological body perspective, which is also appropriate to develop our project, has in the thought of the French philosopher Maurice Merleau-Ponty, the basis for the body to be understood in its lived experience, consisting of dimensions of nature, historicity, spatiality, temporality, language, motricity, intentionality, sexuality, among others. ${ }^{23}$

The body for Merleau-Ponty ${ }^{24}$ is the being itself, the existence of being. Nóbrega ${ }^{25}$ highlights this sensitive knowledge, which is expressed "emblematically, by the esthesia of gestures, love relations, affections, the spoken word and poetic language, among other possibilities of existential experience".

In this sense, in the first month, as seen in Chart 1, meetings were held to, in addition to presenting the project and the ICHP to be developed at the outpatient clinic, promoting discussions about the integral look we should have on the body, about the relationship between pain and quality of life, and also on the taboos of contact with the body.

These discussions were of utmost importance to broaden the conception of the body that is fostered by the biological perspective and allow experiences of how consultations and anamnesis can be conducted when working with the ICHP, and to develop beyond active and welcoming listening, a sensitive look at the signs and history that each body tells in its marks, postures, gestures and habits.

The postural assessment and stretching workshops, therefore, focused on stimulating the perception of the sensitive that the body manifests without using words. For these workshops, Geoffroy's ${ }^{26}$ work was taken as a reference. Stretching plays an important role in the prevention of tendon, muscle or joint problems, regulates postural tonus and muscle recovery, promotes body awareness and prepares muscles for technical gestures or motor performance. ${ }^{26}$

In addition to the projector display, flipcharts (A3) and hospital stretchers were used. Initially, we used the flipchart and drew a checkered plan to make the person's postural assessment, but we also pay attention to the person's expressive signs, feelings, actions and gestures, to understand their habits. After a demonstration of how to perform the assessment, we review the anatomy of postural structures and end with the group experience. We can see these workshops taking place on Figures 1-3. 


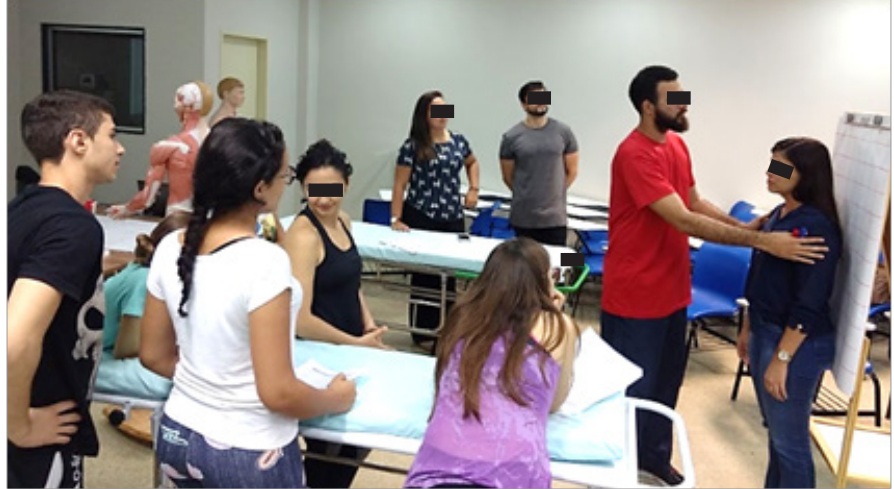

Figure I Postural assessment using flipchart.

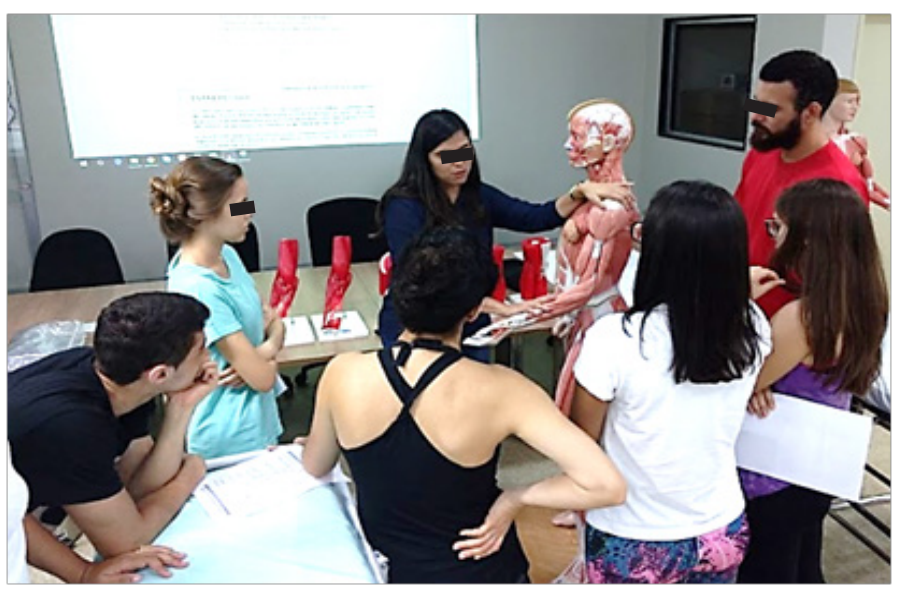

Figure 2 review of the anatomy of postural structures.

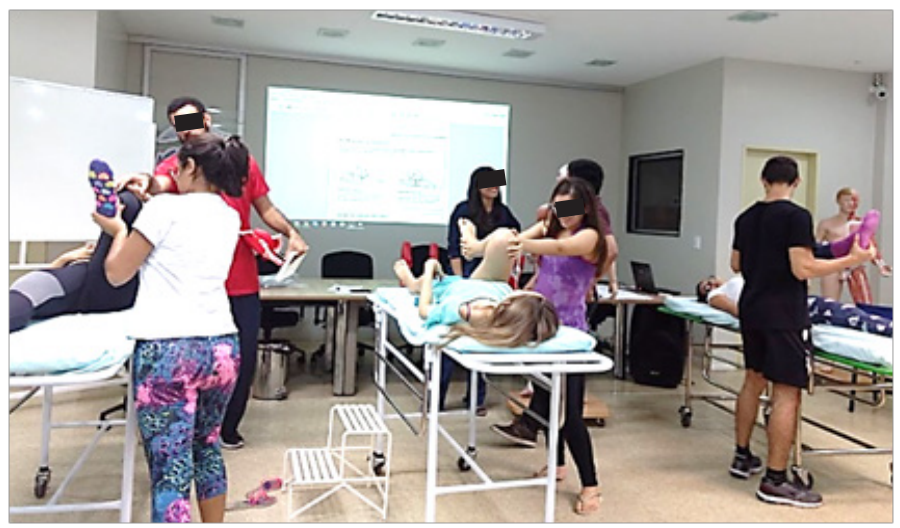

Figure 3 Experience of postural assessment and stretching.

In addition to this workshop that provided a review of postural structures, a meeting was held for a specific study, where one student was the subject to be evaluated and the other examiners. With the help of the anatomy atlas, students identified the subject's back and, through inspection and palpation, the proximal and distal insertions of the superficial muscles of the back. We can see this moment in Figure 4 .

As we can observe, the muscles were then delimited with adhesive tape and then with stereographic pens, the corresponding muscle nomenclature was written and the direction of its fibers was recorded on the tapes. After demarcation, the person performed the movements with that musculature to facilitate memorization and sharpen the perception of location and muscle function to evaluate the other.

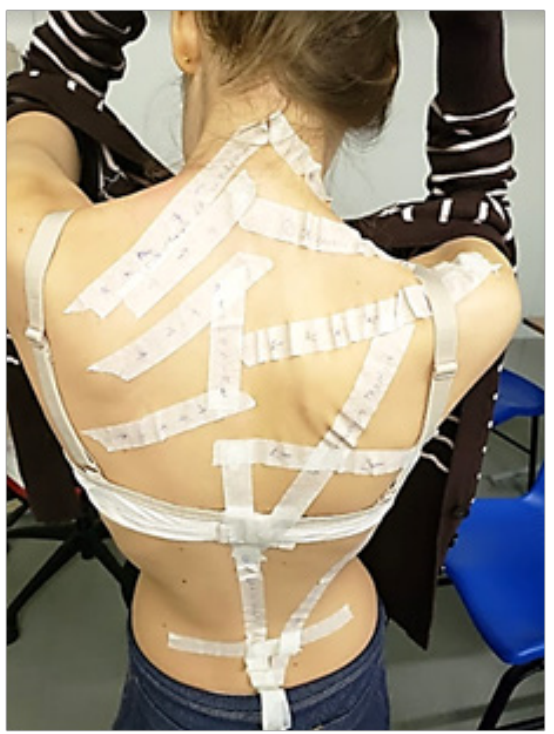

Figure 4 technique for the study of surface anatomy of the back.

In the following month, our meetings were based on the contents of Reflexology and Auriculotherapy. We opened the meeting with a class about the Sympathetic and Parasympathetic Nervous System, understanding its embryonic development until the conclusion of its ramifications in the most developed phases of the body, establishing the relationship with the ear (auricular pavilion) (Figure 5).

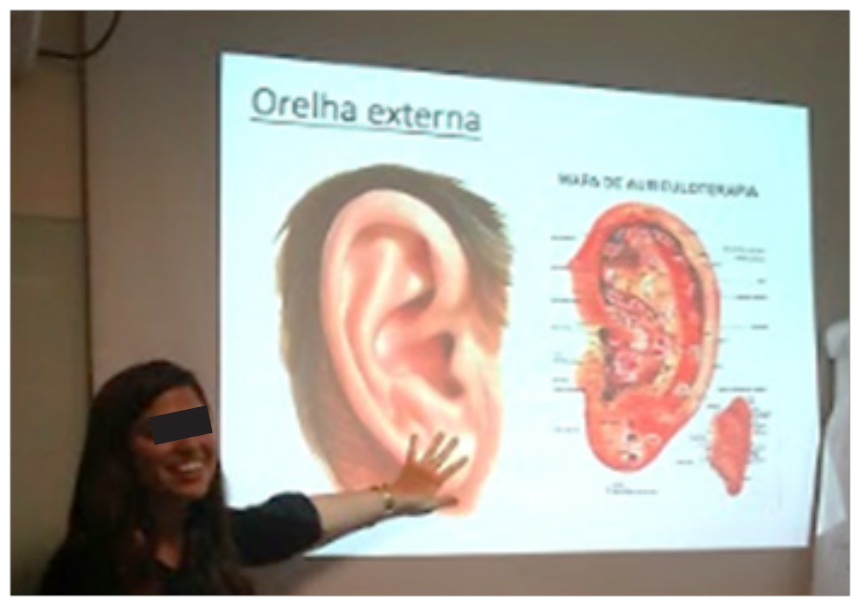

Figure $\mathbf{5}$ Workshop on the nervous system and ear.

In the second session, we had a workshop to review the ear (auricular pavilion) and the technique of painting on paper was used and, in each one, water-soluble and non-toxic paints were used (Figures 6-8).

After this workshop, which promoted knowledge of the auricular pavilion and the nervous system that has influence on it, we started to experience reflexology and auriculotherapy. The basis of application at the outpatient clinic was the material prepared by the Federal University of Santa Catarina (FUSC), ${ }^{27}$ which defines it as "a microsystem therapy, which uses the auricular pavilion to diagnose 
and treat dysfunctions of organic, nervous or somatic origin". ${ }^{27,38}$ In this workshop, Traditional Chinese Medicine, which has been conducting studies and therapeutic practices for more than 2000,000 years, and the French school of Paul Nogier, in 1957, were covered. ${ }^{28}$ At the time, the students were able to know the instruments used and live the experience, under the supervision of the teacher trained in this therapy, as we can see in Figures 9 \& 10.

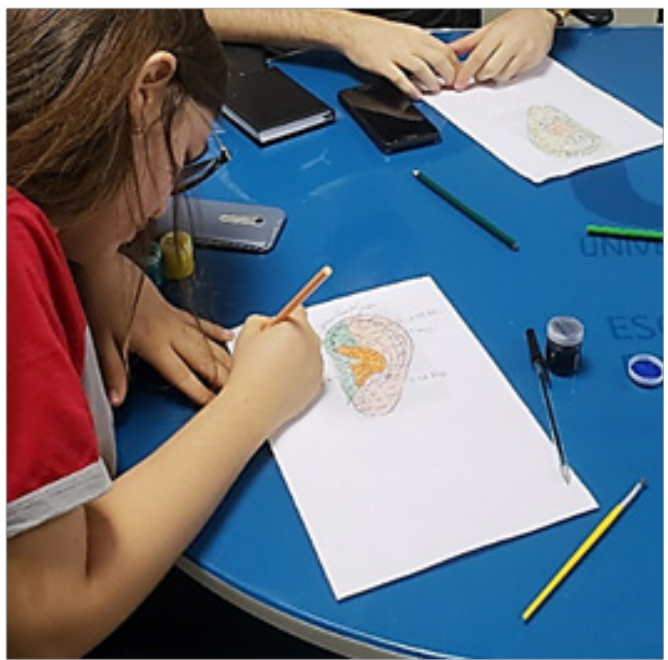

Figure 6 Workshop on ear pavilion.

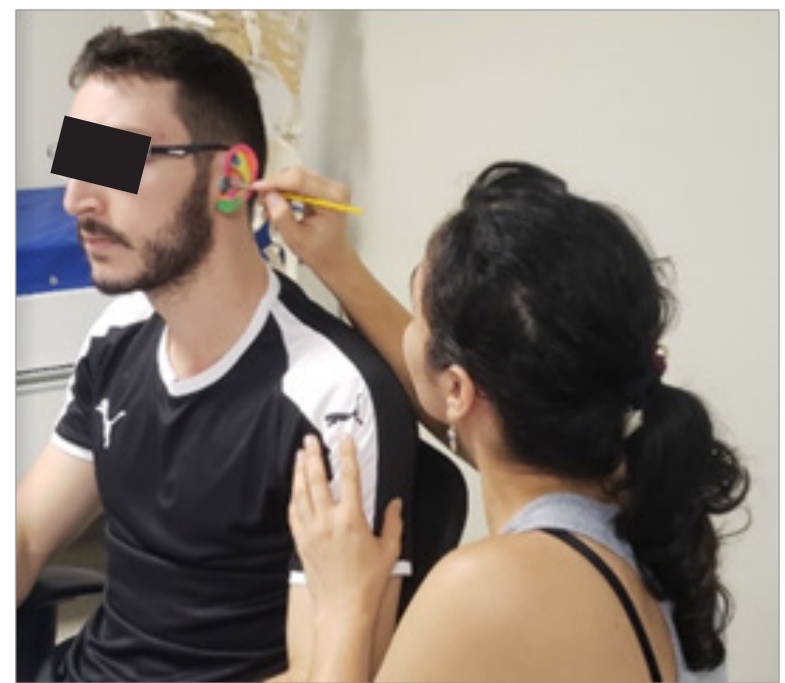

Figure 7 Workshop on ear pavilion.

After the institutional recess, we returned with the activities with massage workshops and studies about muscle biodynamics, especially working on flexion and extension and contraction and relaxation. As an integrative practice, we can ensure the importance of touch, contact, between people. The curative/healing touch is one of the principles that govern massage as a body technique. According to Santos and Silva, ${ }^{29}$ massage provides positive male emotions and relieves stress, being a non-drug resource for self-care and the care of others (Figure 11).

To accompany this moment, the outpatient care promoted students to practice knowledge of massage and the opportunity to develop the look at the other's body regarding the care needs and ways of performing this care. In this sense, perceiving how the other's body behaves, feeling the body temperature, postural alignment, among other elements that, in the person's report, may or may not signal symptoms of pain, muscle tension or tiredness due to emotional exhaustion (Figure 12).

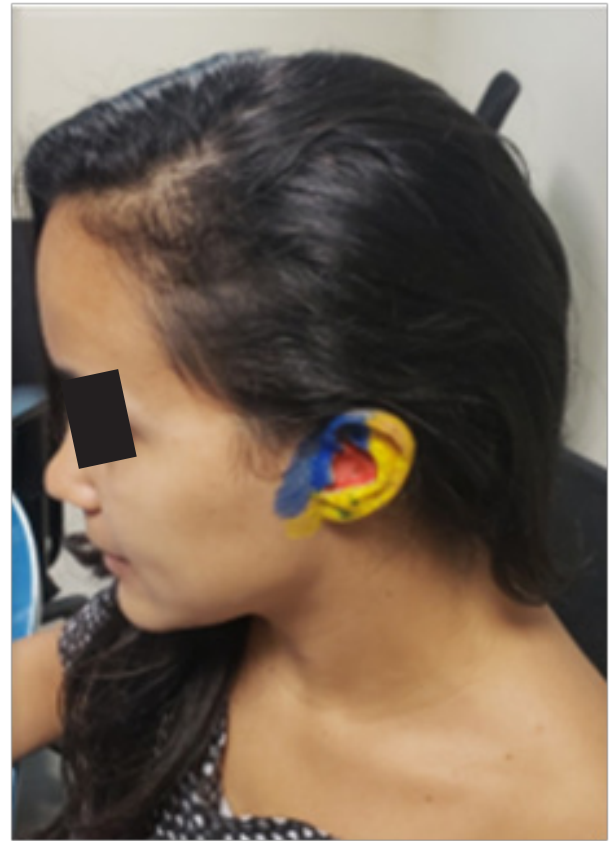

Figure 8 Identification of nerves.

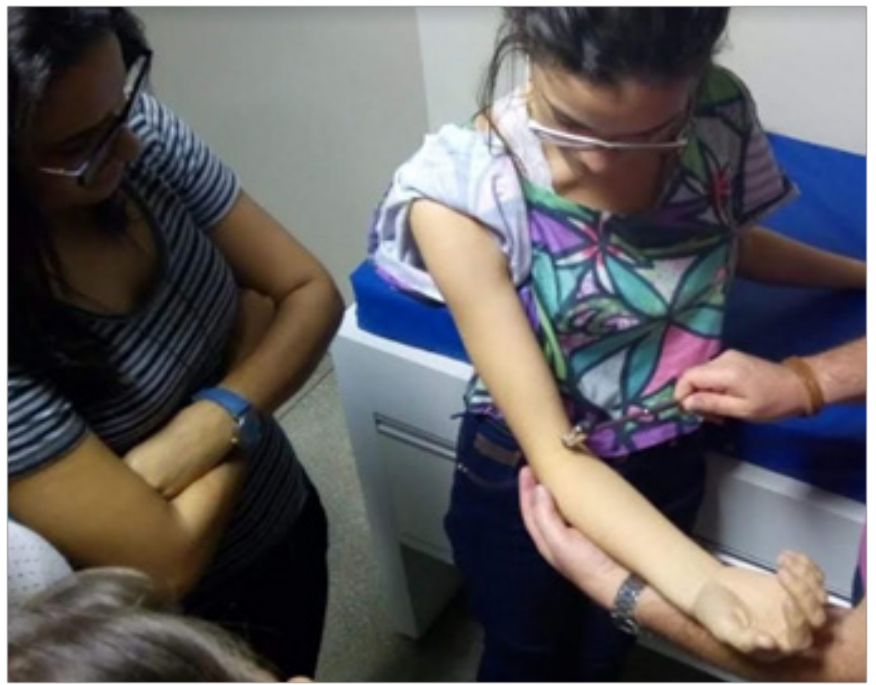

Figure 9 Students experiencing reflexology.

In the second workshop, the learning of the musculature of the deepest layers of the back was worked on. With the use of a commercial human skeleton, atlas book and crochet lines, students wove the origins and insertions of muscle groups, using as a living model one of the subjects who performed the movements with the said musculature (Figures $13 \& 14$ ).

All movements performed by the students with the back muscles were worked in the context of work activities and lifestyle habits, so that they could correlate the anatomy with the main complaints found in outpatient care. 


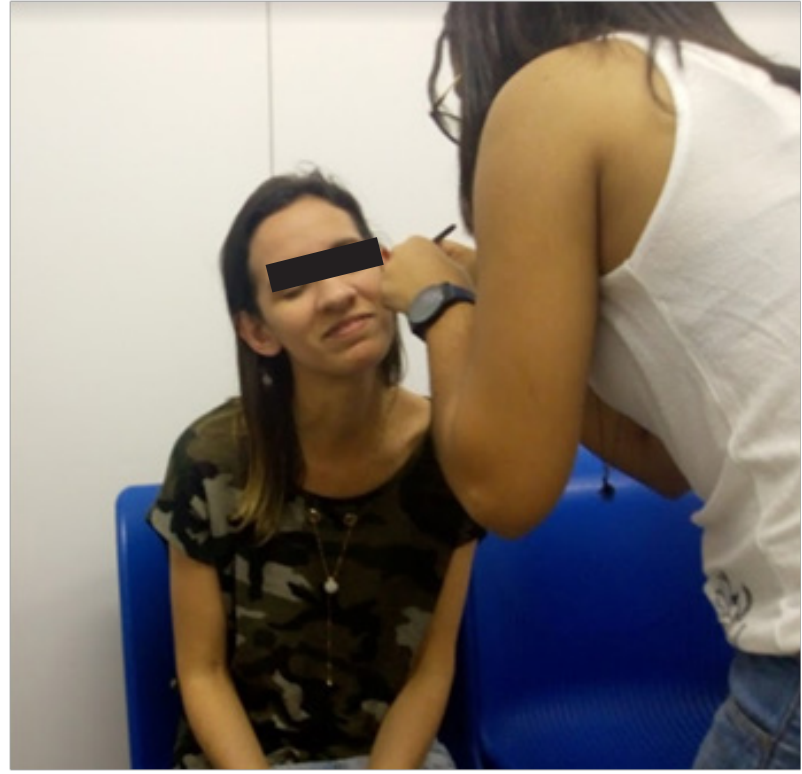

Figure 10 Student performing auriculotherapy in the outpatient clinic.

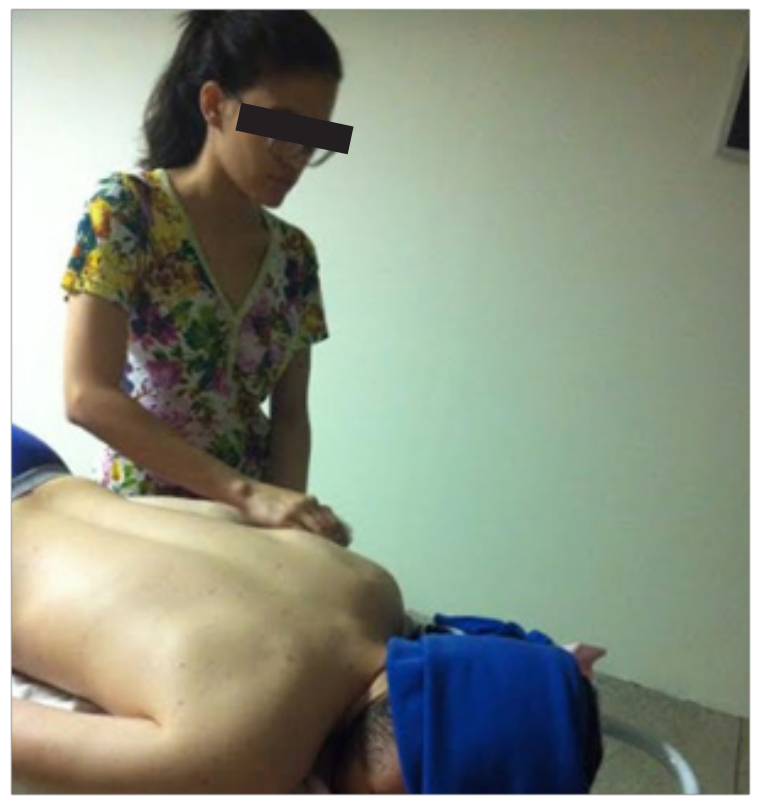

Figure I I Student performing care with massage.

In the next stage, our object of study was trigger-points and cupping therapy. The trigger-points are, clinically, "discrete, hardened and painful nodules, whose pathogenesis is not yet well defined, however, it is believed that this phenomenon is owed to the enclosure of nerve endings in muscle fibers, triggering sensitization". ${ }^{30}$ Trigger-points are considered a Myofascial Syndrome, that is, "a regional painful disorder characterized by the presence of painful points, which causes pain reported in other places different from the origin". ${ }^{30}$

The suction cup therapy is practiced in several countries and uses cups to pull the dermis and muscular tissues, creating the petechiae through the force exerted on the blood that is located under the skin, bringing it to the surface. The benefits are identified through the activation of blood circulation and its possibility to treat a variety of conditions. $^{3}$

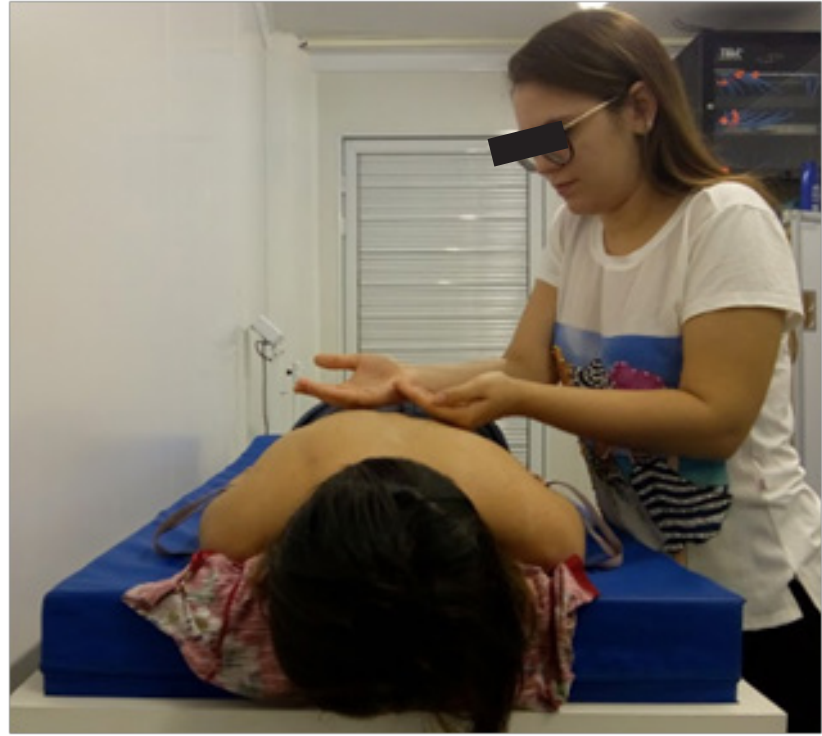

Figure 12 Student body temperature assessment from touch.

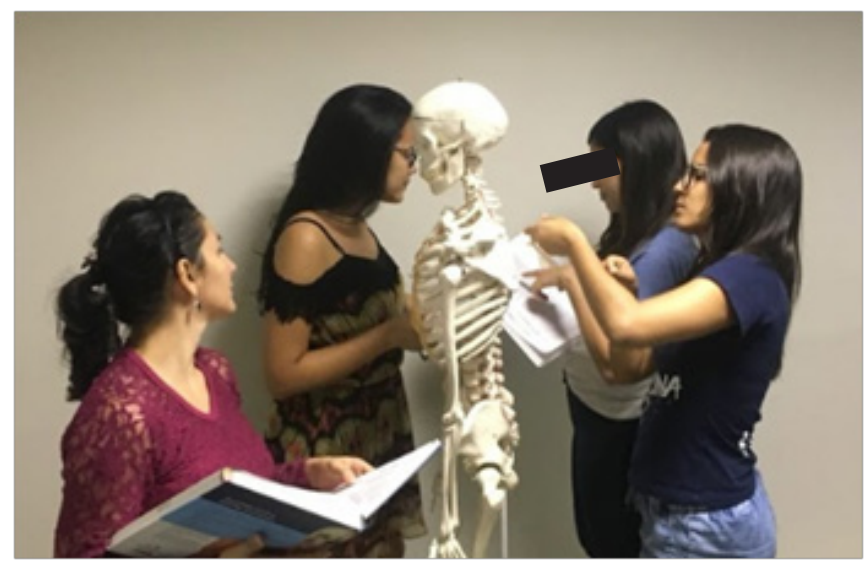

Figure I 3 Study of the deep musculature of the back

At meetings on the topic of myofascial pain, explanations and experiences were made to identify and release tender points from the typing pressure technique. It may be similar to this practice, depending on the therapist's knowledge, shiatsu, or acupressure, which is a practice of pressing the fingers at points that correspond to the same ones used by acupuncture. We can see these meetings from Figures 15 \& 16 .

In turn, tasting therapy is a practice that uses acrylic or glass cups, bamboo cylinders or even horns. This technique works by creating a vacuum or negative force, which promotes the activation of blood circulation, assisting in gas exchange. According to Cunha, ${ }^{32}$ cupping therapy has records from the 4th century BC of Hippocrates, with the use of leeches and buffalo horns. Its benefits are "the increase of white blood cells, increase of red blood cells, improves the anti-hemorrhagic action, makes blood relatively alkaline and strengthens our body's immune system, being an excellent preventive and therapeutic method against diseases". ${ }^{32} \mathrm{We}$ can see the cupping therapy performed on Figures $17 \& 18$.

With the learning of postural structures and having knowledge about how to provide muscle relaxation, we move on to vertebral 
manipulation maneuvers. With the Maitland Concept, it was possible to discuss the relationship between vertebral manipulation and pain control, taking advantage of the knowledge drawn from previous meetings that addressed the nervous system.
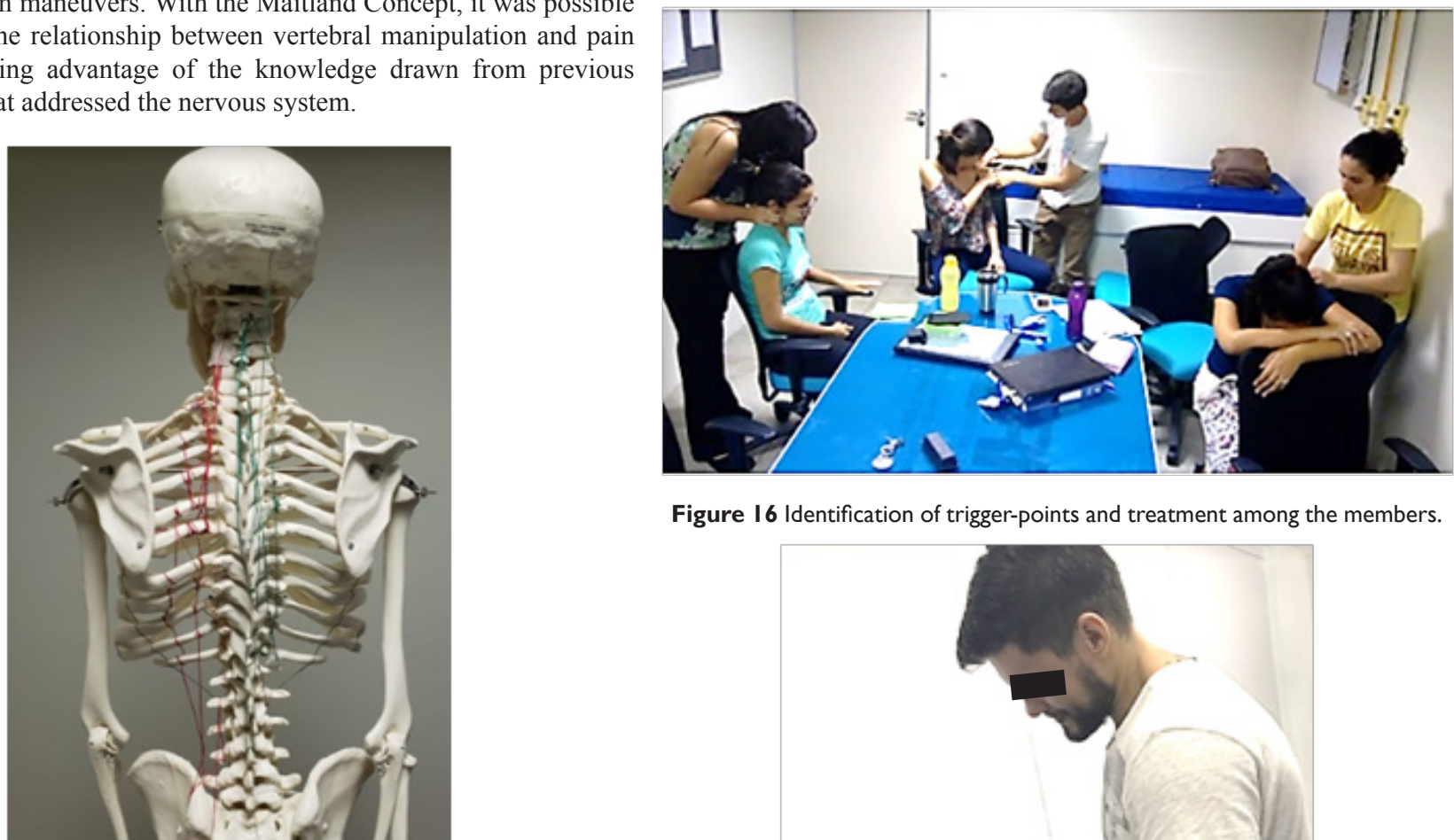

Figure I 6 Identification of trigger-points and treatment among the members.

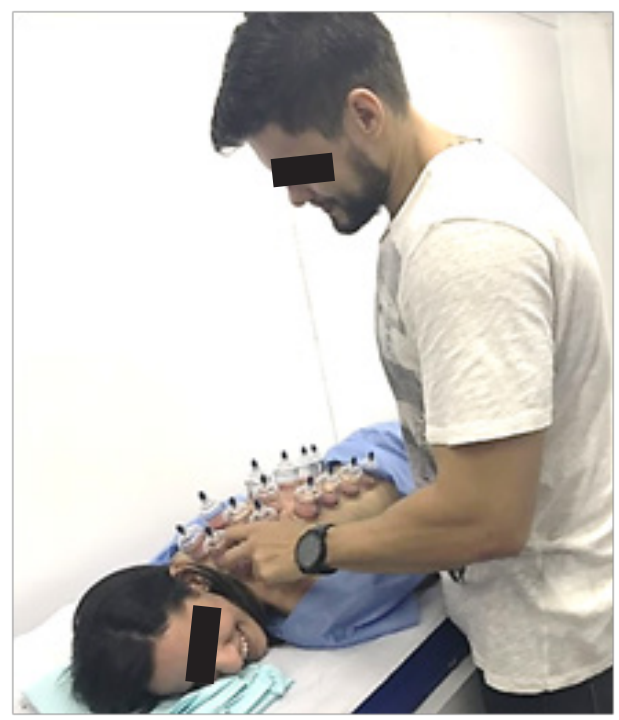

Figure 14 Identification of the deep musculature of the back.

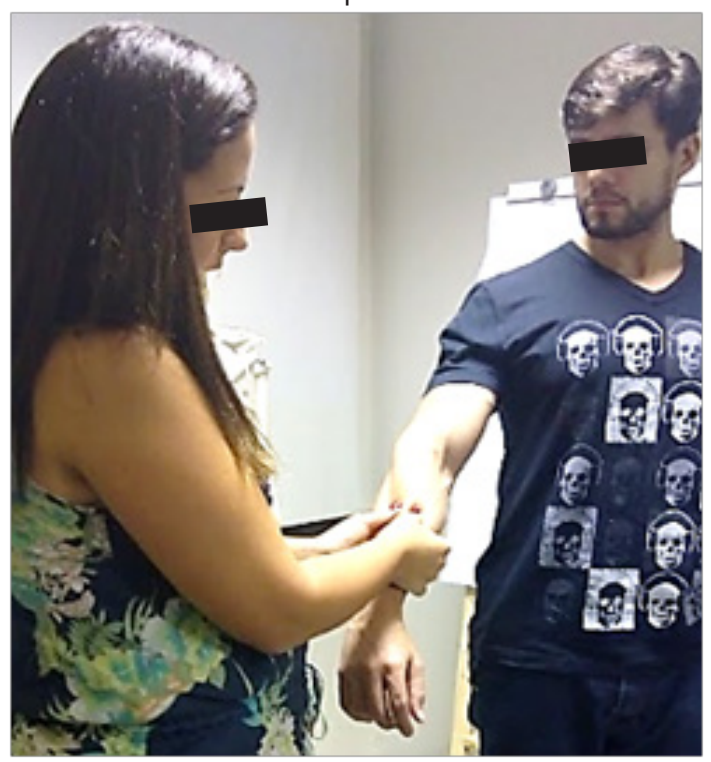

Figure 15 Study on myofascial pain and trigger-points.

According to Tavares et al., ${ }^{33}$ the Maitland Concept has as its characteristics "specific techniques of evaluation and intervention in spinal dysfunctions through joint mobilization and is based on the application of mild passive movements to structures that present decreased range of motion". In turn, Seitai, a practice known as Japanese chiropractic, is a Japanese holistic practice created three centuries ago. ${ }^{34}$ Its characteristic is the energy, muscle and joint manipulation therapy, being a strong resource for skeletal structures and soft tissues, that is, for postural, spinal and cervical conditions. ${ }^{33}$ We can observe the Seitai being performed in Figures $19 \& 20$.

\section{Fig} linic.

Figure 17 Professor performing treatment with cupping therapy in the outpatient clinic.

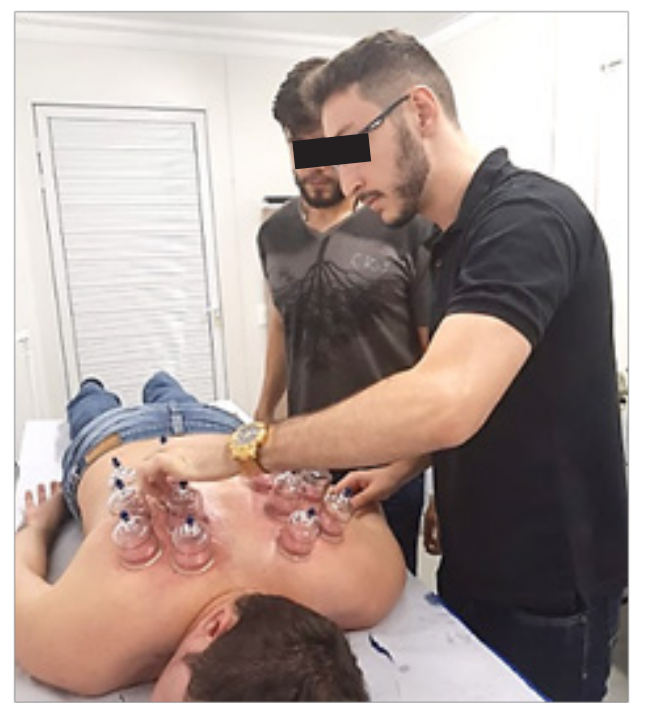

gure 18 Student performing application of cupping therapy in the outpatient 


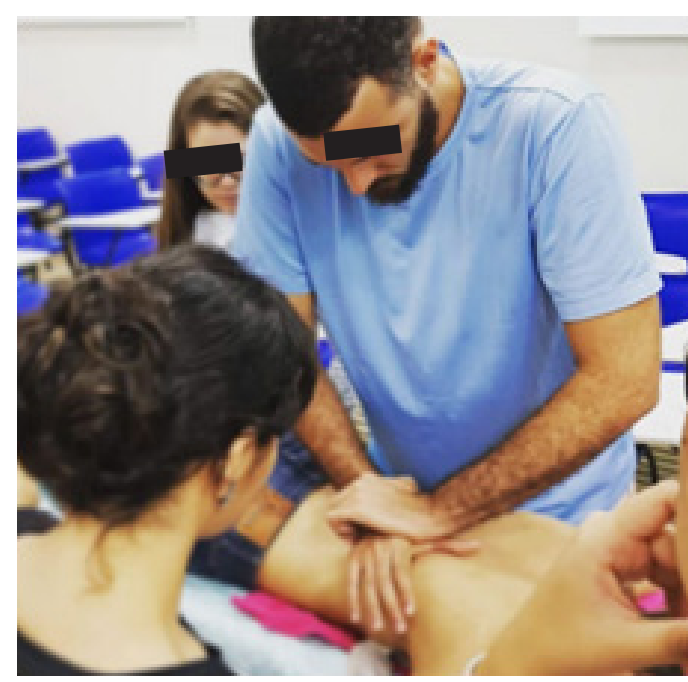

Figure 19 Performing Seitai technique in the outpatient clinic.

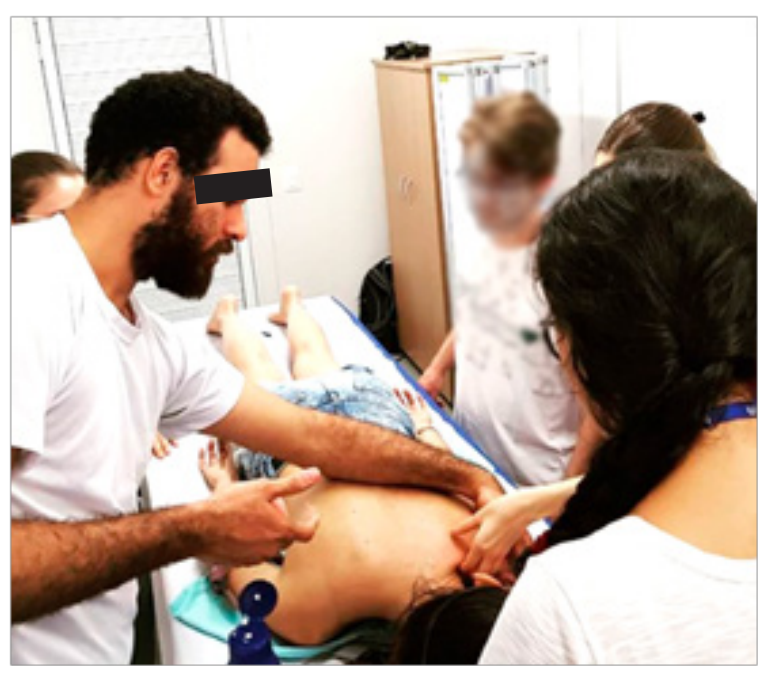

Figure 20 Professor performing Seitai technique in the outpatient clinic.

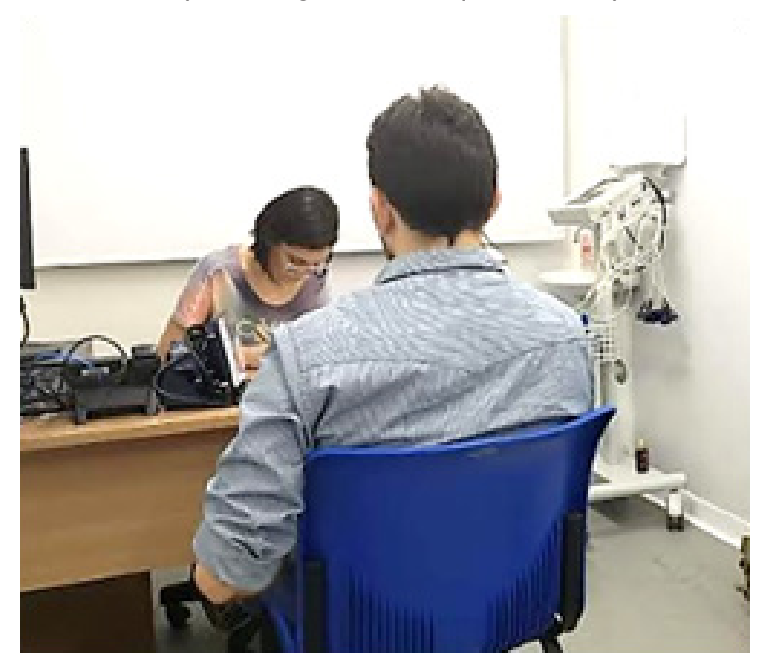

Figure 2 I Student consulting in an outpatient clinic.
After training, students participated in outpatient care. The practice of welcoming listening, inspection and palpation of the muscles to identify signs of muscle tension and pain is essential for the selection of the most appropriate practices that correspond to the needs of each person. With this approach, we were able to have a better idea of the impact of our care on the person's quality of life (Figure 21). In addition to the intervention with ICHP, people also received, at each care, information on how to perform self-care within their life context to promote their own health, such as changes in habits, hydration, sun protection, self-massage, healthy eating, among other recommendations.

Finally, the project enabled the production of academic papers synthesizing techniques for the study of anatomy, which were presented by the students, being guided by the teachers.

\section{Conclusion}

During 2018, the year the project was carried out, our actions were directed towards the development of the surface anatomy technique, in addition to the ICHP, in the MSMS medical course. The union of ICHP in the teaching and learning process of surface anatomy corroborated a formation in which care became the axis of learning and may have repercussions on the future professional performance of these students. The superficial anatomy workshops allowed a better appropriation of the anatomical structures and the relationship between tension and pain of muscular origin with quality of life, and can also intervene holistically in the promotion of care for others.

With the visualization of the structures, its points of origin and insertion, it was possible to evaluate its dimensions, mobility and functions, beyond its limits. Once the muscles were demarcated, the palpations allowed to know the muscle constitution, its density and also its location and movements. The singularity in each body increased the sensitivity to possible changes and pathologies that caused tension and pain points. We focused on pain arising from muscle tension, such as trigger points or compromised stretching and muscle flexibility, so that the students themselves could participate in the treatment in the outpatient clinic, improving the quality of life of the person and increasing their learning.

In the special case of the meeting in which the anatomy of the pinna and the studies with reflexology were discussed, the nerve ramifications were approached by a Western biomedical perspective, Traditional Chinese Medicine and the French school of Paul Nogier. Embryological and histological questions were raised to explain how Western anatomy and Eastern medicine correlate, being recognized as a possibility of treating a series of disorders, whether of an energetic, physical or emotional nature. With this workshop, we also realized that it is possible to treat muscle pain and tension, helping to recover muscle tone through stimulation points in the ear.

The workshops, therefore, allow a redirection of the appearance that comes out of books with dimensional Figures and anatomical parts always static, so that the presence and uniqueness of each human body can be felt. The contact with the other, through touch, also allowed the creation of a greater bond, improving the students' accuracy in properly evaluating important superficial anatomical structures that may be relevant in his future medical practice.

Experience and the study of surface anatomy are thought to be dynamic and versatile, providing greater practicality and sensitivity 
in the production and appropriation of knowledge. The use of manual materials, together with the opportunity to treat volunteers in the outpatient clinic, who gave their bodies their unique and dynamic nature of life, has proven to be a process that facilitates the apprehension of knowledge, affirming the construction of an efficient didactic-methodological tool for learning human anatomy and the ICHP. It is therefore necessary to innovate the anatomy experience in these courses, often following the traditional format of dissection and study of pieces in the laboratory, which in turn is characterized as one of the main barriers found. We then promote the possibility of expanding the forms of teaching and learning, linking them to the ICHP and the technique of surface anatomy.

Moreover, with the consent of each person assisted in the outpatient clinic, we were able to feel and analyze their bodies for the teachinglearning of the ICHP, also reinforcing that we still need to learn about touch, the cultural symbols that form taboos, prejudices, the notion of modesty that are socially constructed and are elements present in the routine of medical practice.

\section{Acknowledgments}

We would like to thanks the Multicampi School of Medical Sciences of Rio Grande do Norte, Federal University of Rio Grande do Norte, University of Pernambuco, Federal University of Paraíba, Higher Education Personnel Development Coordination (CAPES).

\section{Funding}

Pro-Rectory of Extension of the Federal University of Rio Grande do Norte; Higher Education Personnel Development Coordination (CAPES).

\section{Conflicts of interest}

The authors declare no conflict of interest.

\section{References}

1. Bergman EM, Prince KJ, Drukker J, et al. How much anatomy is enough? Anat Sci Educ. 2008;1(4):184-188.

2. Bergman EM, Sieben JM, Smailbegovic I, et al. Constructive, collaborative, contextual, and self-directed learning in surface anatomy education. Anat Sci Educ. 2013;6(2):114-124.

3. Reis C, Martins MD, Mendes RAF et al. Evaluation of how medical students perceive anatomical study. Rev Bras Educ Med. 2013;37(3):350-358.

4. Oliveira RCU, Tinôco JDS, Delgado MF, et al. An educational strategy for teaching human anatomy to nurses. Av Enferm. 2018;36(1):31-39.

5. Taylor JR, Wilson AS. Letter: Prognosis for anatomy. Lancet. 1975;14;1(7920):1334.

6. Salve MGC, Bankoff ADP. Postura corporal - um problema que aflige os trabalhadores. Rev Bras Saúde Ocup. 2003;28(105-106).

7. Gabriella H, Henrik S, Zoltán K. Acupuncture and pain (survey on literature). Int J Complement Alt Med. 2018;11(4):222-226.

8. Teixeira EP, Ferreira JB. Postural deviations in Brazilian students: a literature review. Educational Scenes Magazine. 2019;2(1):81-106.

9. Webb AL, Green RA, Woodley SJ. The development of a core syllabus for teaching musculoskeletal anatomy of the vertebral column and limbs to medical students. Clin Anat. 2018;6.
10. Andrade FA, Portella CFS. Research methods in complementary and alternative medicine: an integrative review. $J$ Integr Med. 2018;16(1):16-13.

11. https://bvsms.saude.gov.br/bvs/publicacoes/declaracao_alma_ata.pdf

12. Joos S, Musselmann B, Miksch A, et al. The role of complementary and alternative medicine (CAM) in Germany - a focus group study of GPs. BMC Health Serv Res. 2008;8(127).

13. Okoronkwo I, Onyia-Pat JL, Okpala P, et al. Patterns of Complementary and Alternative Medicine Use, Perceived Benefits, and Adverse Effects among Adult Users in Enugu Urban, Southeast Nigeria. Evid Based Complement Alternat Med. 2014;2014:239372.

14. Davis MA, Martin BI, Coulter ID, et al. US spending on complementary and alternative medicine during 2002-08 plateaued, suggesting role in reformed health system. Health Aff (Millwood). 2013;32(1):45-52.

15. Brazil. National policy of integrative and complementary practices in the SU: attitude of expansion of access. 2nd edn. Brazil: Ministry of Health; 2015

16. Nascimento CM, Tesser CD, Sousa MC. Traditional, complementary and int Segrative medicines in the Brazilian health primary care. Int $J$ Complement Alt Med. 2019;12(6):246-248.

17. Gonçalves MAS. Feeling, thinking and acting: corporeity and education. 2nd edn. Campinas: Papirus; 1997.

18. Zoboli F, Bordas MAG. Body, stigma and (in)exclusion in the school environment. In: DANTAS Junior HS, Kuhn R, Ribeiro SDD, editors. Physical Education, Sport and Society: Emerging Themes. Saint Kitts: Editora UFS; 2010. p. 83-98.

19. Jong MC, van de Vijver L, Busch M, et al. Integration of complementary and alternative medicine in primary care: what do patients want? Patient Educ Couns. 2012;89(3):417-422.

20. Garcia RA. Yoga and meditation: integrating mind-body medicine into a workplace wellness program. Police agency organizational and implementary considerations. Int $J$ Complement Alt Med. 2019;12(2):92-95.

21. Ke H. Modern holistic medicine from the perspective of traditional chinese medicine. Int J Complement Alt Med. 2019;12(3):115-120.

22. Fensterseifer PE. Body, modernity and school. Corporalogia. 2008;1(1)19-26.

23. Medeiros RMN. From the anatomical body to the phenomenological body: different perspectives to think about the body. Experience. 2011;(37):141-149.

24. Merleau-Ponty M. Phenomenology of perception. Translation Carlos Alberto Ribeiro de Moura. 4th edn. São Paulo, Brazil: Martins Fontes; 2011.

25. Nóbrega TP. Body, perception and knowledge in Merleau-Ponty. Estudos de Psicologia. 2008;13(2):141-148.

26. Geoffroy C. Alongamento para Todos. São Paulo: Manole; 2001.

27. Universidade Federal de Santa Catarina (UFSC). Formação em Auriculoterapia: para profissionais de saúde da atenção básica. Florianópolis: UFSC; 2016.

28. Artioli DP, Tavares ALF, Bertolini GRF. Auriculotherapy: neurophysiology, choice points, indications and results in painful musculoskeletal conditions: systematic review of reviews. Br J Pain. 2019;2(4):356-361

29. Santos JB, Silva JAB. Therapy through massage: massotherapy in the 
psychosocial care center of Amargosa/BA. Ghetto. 2015;1(1):120-134.

30. Maciel APO, Dominguete MHL, Topical anesthetic to trigger trigger points in myofascial pain syndrome. Pilot study. $\mathrm{Br} J$ Pain. 2018;1(2):147-150

31. Dinall AM. A reflection on cupping therapy and historical medical dominance. Int J Complement Alt Med. 2019;12(2):66-68.

32. Cunha AA. Ventosaterapia. São Paulo, Brazl: Ícone; 1996.
33. Tavares FAG, Chaves TC, Silva ED, et al. Immediate effects of joint mobilization in relation to the sham and control intervention on pain intensity and disability in patients with chronic low back pain: randomized controlled clinical trial. Rev Dor. 2017;18(1):2-7.

34. Teixeira LMA. Integrative and complementary practices: corpora analysis and bilingual glossary. São Paulo: USP. 2018. p. 192. 